\title{
EXPERIMENTAL AND THEORETICAL STUDY ON THE BEHAVIOR OF THE STEEL-CONCRETE COMPOSITE BEAM WITH NOTCHED WEB OF INVERTED T-SHAPED STEEL SECTION AT CONSTRUCTION STAGE
}

\author{
Guo-Qiang $\mathrm{Li}^{1,2,{ }^{*}}, \mathrm{Li}$ Liang ${ }^{2}$ and Xianhui $\mathrm{Li}^{2}$ \\ ${ }^{1}$ State Key Laboratory for Disaster Reduction in Civil Engineering, \\ Tongji University, Shanghai 200092, People's Republic of China \\ ${ }^{2}$ College of Civil Engineering, Tongji University, Shanghai 200092, People's Republic of China \\ *(Corresponding author: E-mail: liliang.tj@163.com)
}

Received: 1 March 2011; Revised: 2 April 2011; Accepted: 12 April 2011

\begin{abstract}
The behavior of the steel-concrete composite beam with notched web of inverted T-shaped steel section at construction stage is investigated in this paper. The composite beam is composed of concrete slab and inverted T-shaped steel beam, and the notched web of the steel beam is embedded in concrete slab as trapezoid shear connectors. When the strength of the concrete has not been fully developed at construction stage and the steel beam with inverted T-shaped section is likely to buckle in lateral direction. For preventing this, using cushion blocks at the bottom flange of the steel beam to support the vertical load during the construction of the composite beam is proposed. The experimental studies on four specimens are conducted to investigate the behavior of the steel beam with notched web of inverted T-shaped steel section at the construction stage. The theoretical analysis is carried out for critical buckling capacity of the composite beam with loads on single or both sides of the web and formulas for predicting the critical capacity of the beam are proposed respectively. The effectiveness of the formulas is verified by comparing the predicted results of the specimens' tests with the results measured from tests and obtained with FEM.
\end{abstract}

Keywords: Inverted T-shaped steel section, Construction stage, Trapezoid connectors, Critical buckling capacity, FEM analysis

\section{INTRODUCTION}

The conventional composite beam is composed of steel beam with $\mathrm{H}$-shaped section and concrete slabs [1-6], and headed studs are used as shear connectors to combine the steel beam and concrete slab together, as shown in Figure 1 (a). In the H-shaped steel concrete composite beams, the top flange of the steel beam is at the vicinity of the neutral axis of the section, its stress level is low and its contribution to the moment-resistance of the composite beams is little [7-9]. The steel-concrete composite beam with notched web of inverted T-shaped steel section is formed by removing the top flange of the H-shaped steel beam [10], which reduces the cost of steel and avoids the wielding process by replacing headed studs with the trapezoid connectors, generally designed to bear sagging moment, as shown in Figure 1 (b).

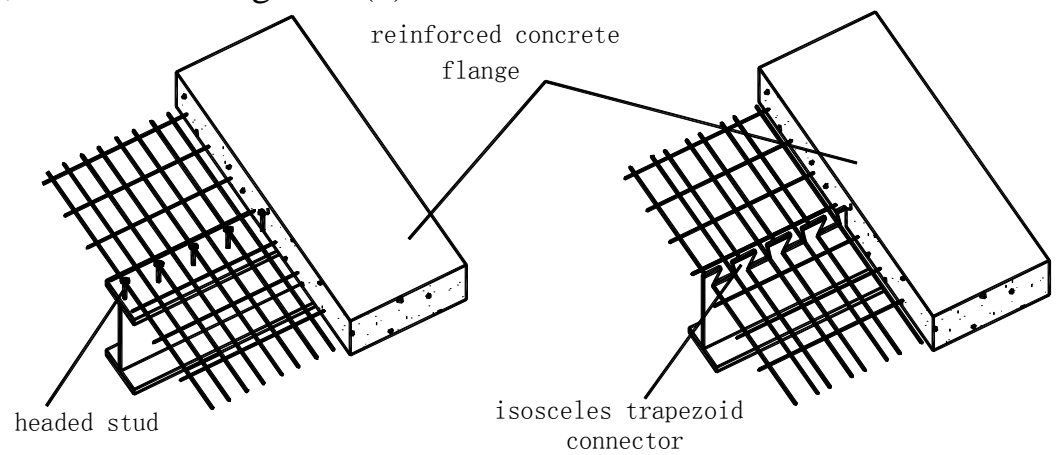

(a) H-shaped Steel-concrete Composite Beam

(b) Steel-concrete Composite Beam with Notched web of inverted T-shaped steel section

Figure 1. Steel-concrete Composite Beam with Different Connectors 
In order to study the behavior of the novel composite beam, a series of tests have been conducted in Tongji University ( $\mathrm{Li}$ and Li [11-12]). The shear behavior of the trapezoid connector was tested through six specimens [11], and the results showed that the shear capacity of the trapezoid connector was strong enough to pledge the fully shear connection between concrete slab and steel beam. The pull-out behavior of the connector was also studied through the test of 6 pull-out specimens [12], and the results showed that the pull-out capacity was much larger than $10 \%$ of the shear capacity, and the connector could supply enough pull-out capacity between the concrete slab and steel beam.

However, at the construction stage, when the strength of the concrete slab is not fully developed, the construction loads are merely undertaken by the steel beam. At this stage, the lateral buckling of the steel beam with inverted T-shaped section may happen. Considering that the buckling of the steel beam is sensible to the loading pattern, it is suggested that the cushion blocks are placed on the bottom flange of the steel beam to transform the construction load to the lower loading position on the steel beam. Thus the stability of the steel beam can be improved, as is shown in Figure 2. As metal decking is employed in this novel composite beam with notched web, the concrete form board would be replaced by cold-formed steel sheet to play the bottom formwork.

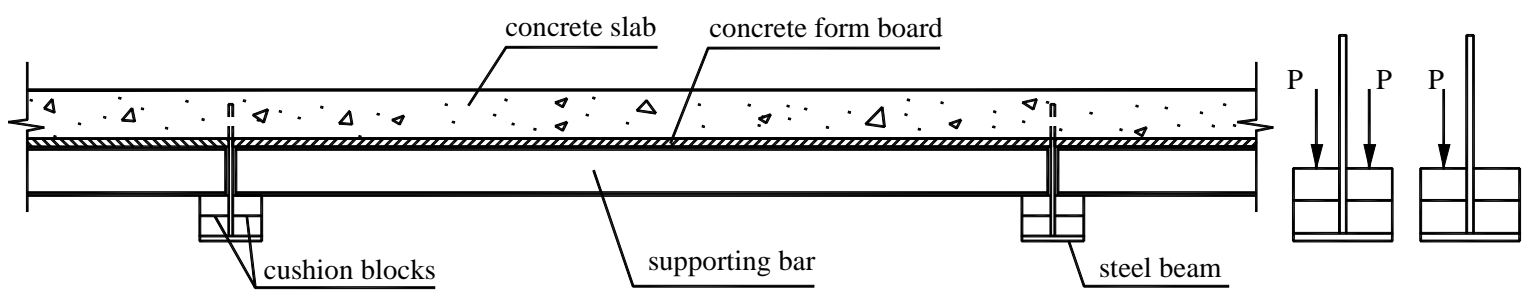

Figure 2. Construction of Embedded Composite Beams

As a kind of novel structural components, the behavior of the steel-concrete composite beam with notched web of inverted T-shaped steel section at construction stage needs to be clearly identified for proper design and application. The flexural torsion buckling capacity of the steel beam with inverted T-shaped section subjected to symmetrical and un-symmetrical loading is studied experimentally and theoretically. The formulas for predicting the capacity of the steel beam at the construction stage of the novel steel-concrete composite beam are proposed.

\section{EXPERIMENTAL STUDIES}

\section{$2.1 \quad$ Specimens}

To study the overall stability capacity of the steel beam with inverted T-shaped section, experimental studies were conducted on four specimens in the Structural Laboratory of Tongji University. The specimens TB- 1 and TB-2 are the same as the specimens TB-3 and TB-4 respectively. The dimensions of the specimens are shown in Figure 3. The detail information of the specimens is given in Table 1. The yielding strength of the steel for the specimens is $300 \mathrm{MPa}$, and the tensile strength is $380 \mathrm{MPa}$, obtained from the material test.

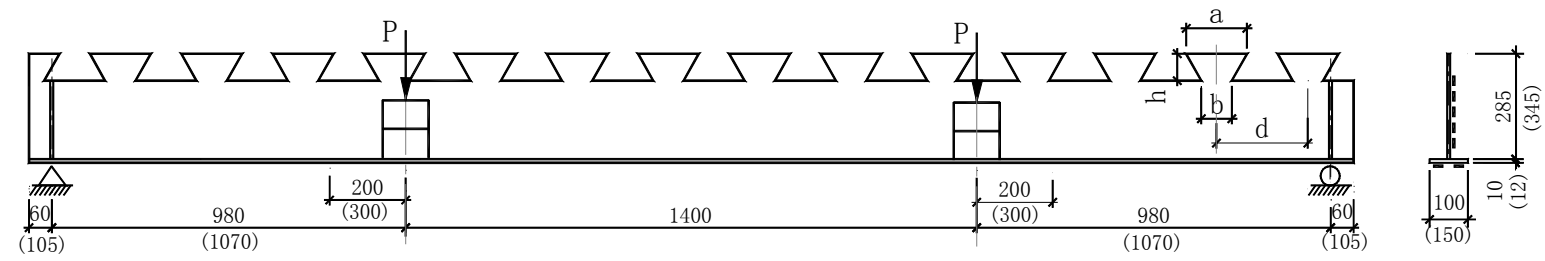

Figure 3. Detailing of the Specimens TB-1, TB-2 (TB-3, TB-4) 
Table 1. Information of Specimens

\begin{tabular}{c|ccc}
\hline Specimens & $T B-1$ & $T B-2$ & $T B-3$ \\
\hline Load mode & Symmetrical un-symmetrical & symmetrical un-symmetrical \\
Web $(\mathrm{mm} \times \mathrm{mm})$ & $215 \times 8$ & $265 \times 10$ \\
Flange $(\mathrm{mm} \times \mathrm{mm})$ & $100 \times 10$ & $150 \times 12$ \\
Beam span $(\mathrm{mm})$ & 3360 & 3640 \\
Shear span $(\mathrm{mm})$ & 980 & 1070 \\
$a(\mathrm{~mm})$ & 160 & 200 \\
$b(\mathrm{~mm})$ & 80 & 100 \\
$h(\mathrm{~mm})$ & 70 & 80 \\
$d(\mathrm{~mm})$ & 240 & 300 \\
\hline
\end{tabular}

Note: $a, b, h$ and $d$ are the geometries indicated in Figure 3

\section{$2.2 \quad$ Test Set-up and Measurement}

The Hydraulic Jack is used as the loader, and the wooden blocks are used as cushion block. All of the specimens are simply supported. The specimens TB- 1 and TB-3 are loaded on both sides of the steel beam web, and the specimens TB-2 and TB-4 are loaded on only one side of the web, as is shown in Figure 4.

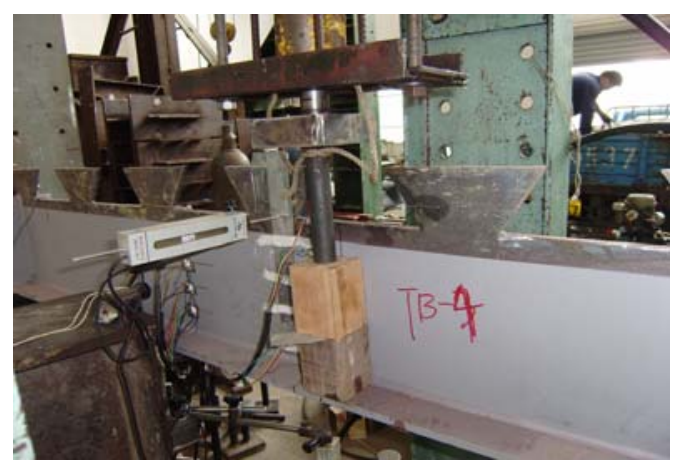

(a) Loading at One Side of the Steel Beam Web

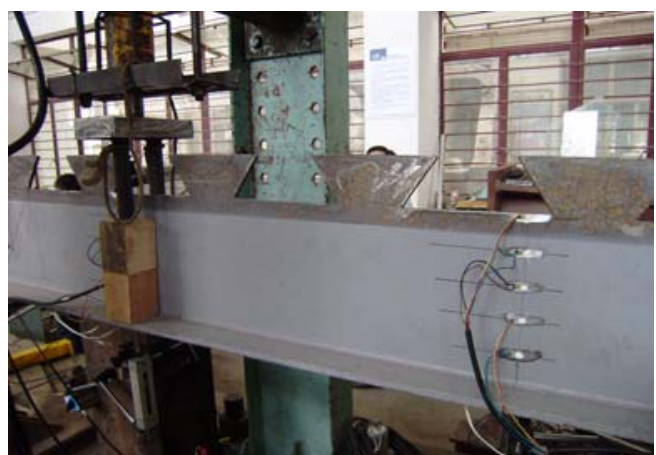

(b) Loading at Both Side of the Steel Beam Web

Figure 4. Test Set-up of the Steel Beam

Eight displacement meters were arranged for the measurement. The vertical and lateral displacements at the location of the middle span and the two loading points were measured by displacement meters $\mathrm{d} 1 \sim \mathrm{d} 6$; the displacement meters $\mathrm{d} 7 \sim \mathrm{d} 8$ were set to measure the displacement of the specimen at supports as shown in Figure 5. A total of twenty one strain gauges and 8 strain rosettes were arranged for each specimen at the position, as shown in Figure 6.

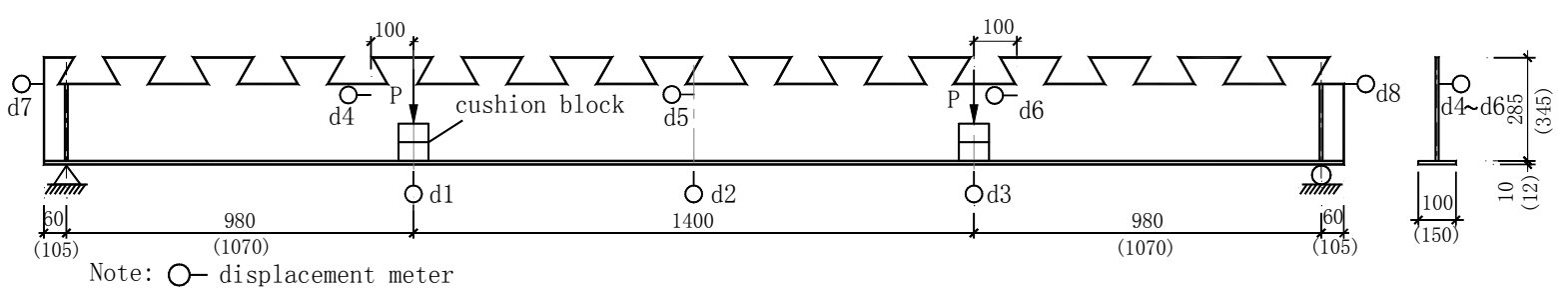

Figure 5. Arrangement of Displacement Meters on Specimens TB-1, TB-2 (TB-3, TB-4) 


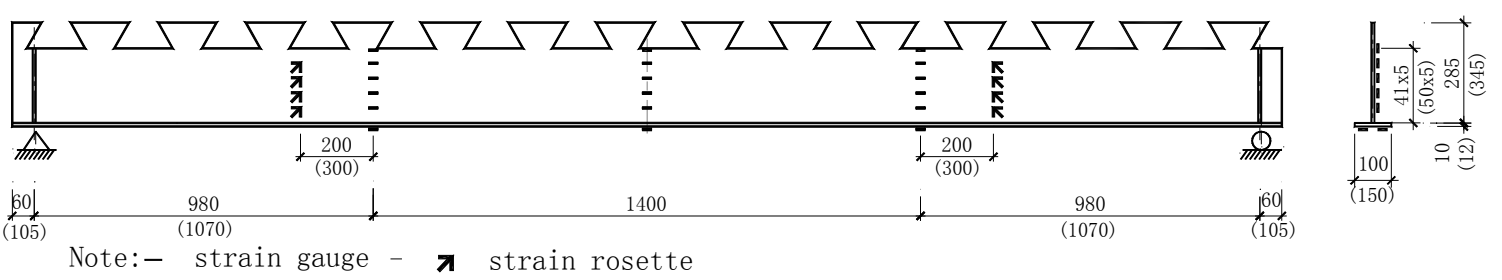

Figure 6. Arrangement of the Strain Gauges on Specimens TB-1, TB-2 (TB-3, TB-4)

\section{$2.3 \quad$ Test Results}

The strains of mid-span section of the specimens are shown in Figure 7. It can be found that the strain distribution along the cross-sectional height of the steel beam is nearly linear. Since the specimens TB-1 and TB-3 were symmetrically loaded on both sides of the steel beam web, the larger load can be beard than that by TB-2 and TB-4 and the maximum strain of the steel beam for TB-1 and TB-3 can reach plastic stage, as shown in Figure 7 (a) and (c). On the other hand, the specimens TB-2 and TB-4 were un-symmetrically loaded on one side of the steel beam web, the torsional and lateral instability of the steel beam may happen at elastic stage, as shown in Figure 7 (b) and (d).

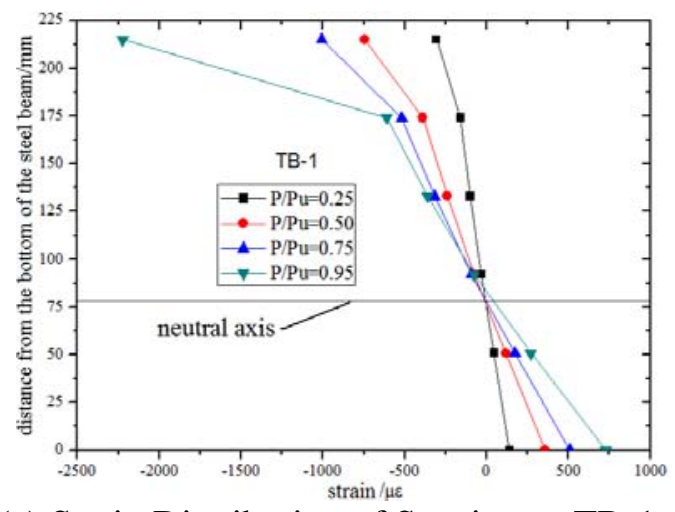

(a) Strain Distribution of Specimens TB-1

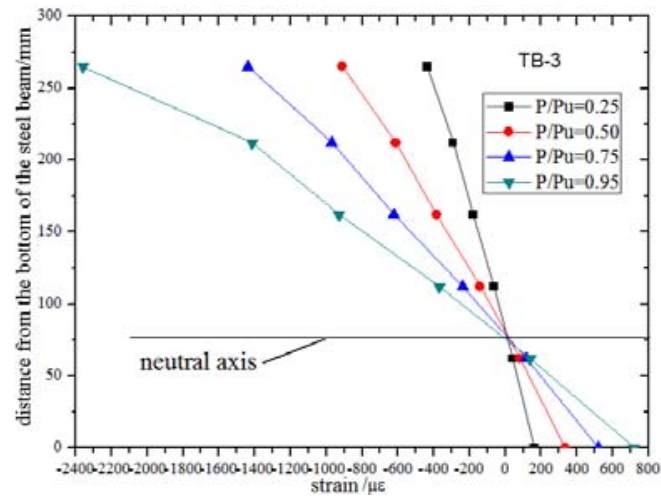

(c) Strain Distribution of Specimens TB-3

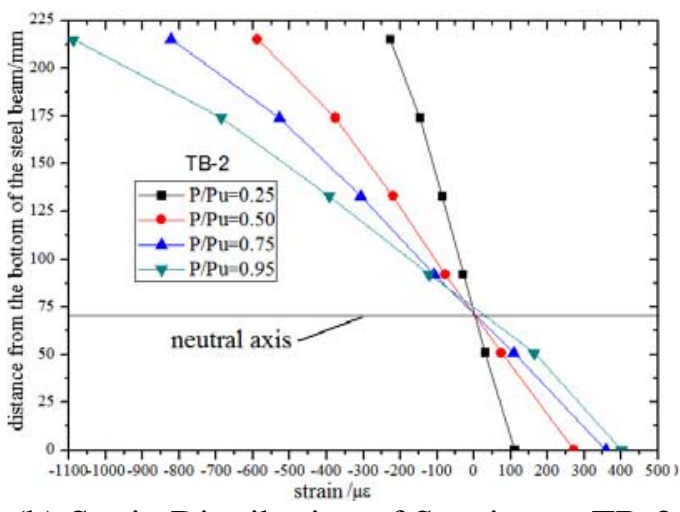

(b) Strain Distribution of Specimens TB-2

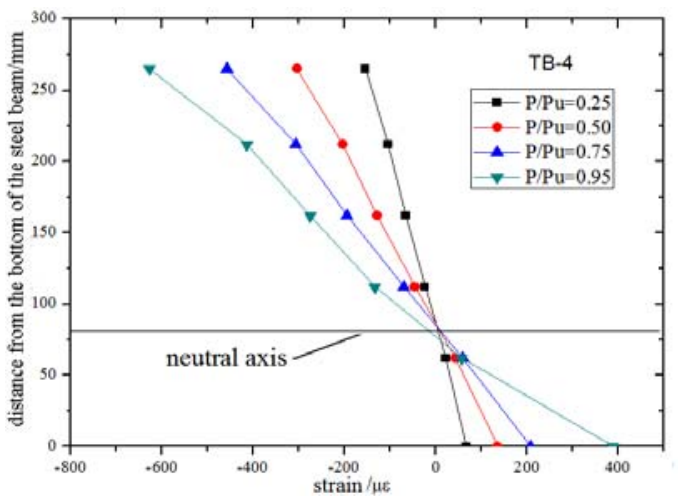

(d) Strain Distribution of Specimens TB-4

Figure 7. Strain Distribution along the Cross-sectional Height of the Section at Middle Span 
Measured load-deflection curves of the specimens are shown in Figure 8, in which X-coordinate is lateral or vertical deflection, and y-coordinate is the load. Since specimens TB-1 and TB-3 were symmetrically loaded, the vertical deflection was much larger than the lateral deflection. On the other hand, the specimens TB-2 and TB-4 were un-symmetrically loaded, torsion was developed in the specimens, which led to that the lateral deflection is much larger than the vertical deflection.

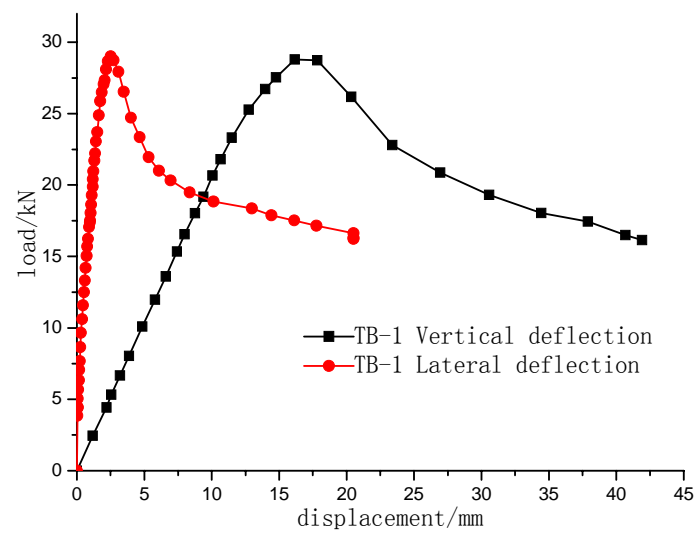

(a) Curves of Specimens TB-1

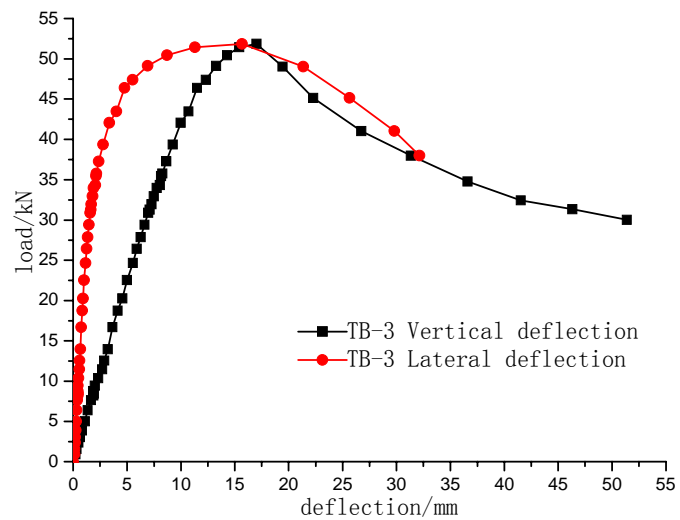

(c) Curves of Specimens TB-3

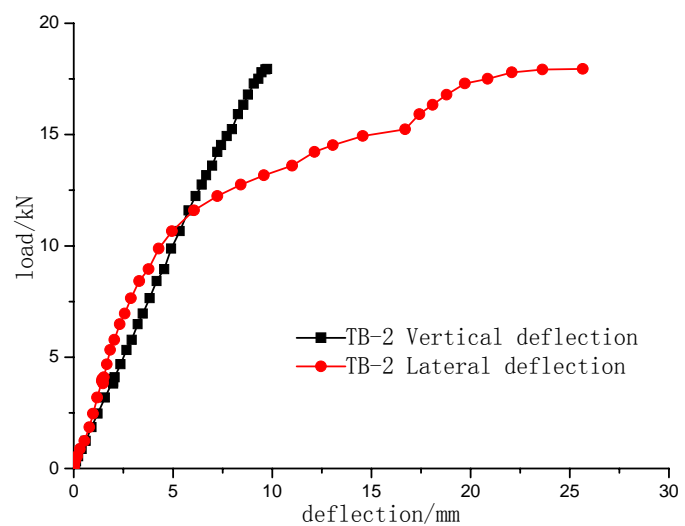

(b) Curves of Specimens TB-2

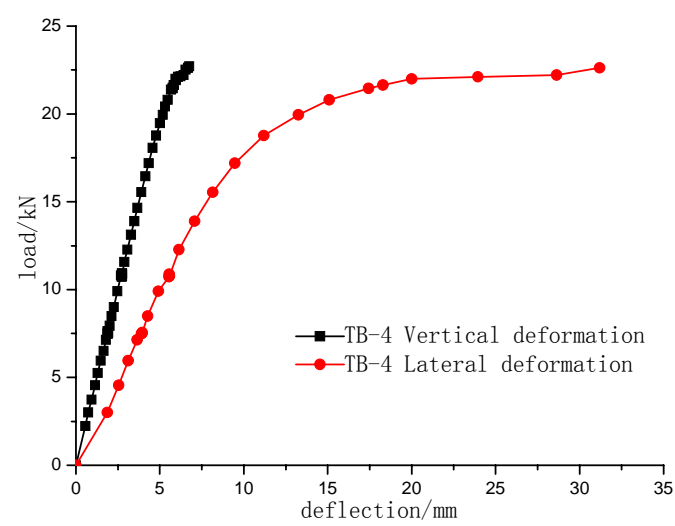

(d) Curves of Specimens TB-4

Figure 8. Measured load-deflection curves of the specimens

\section{ANALYTICAL STUDIES}

\subsection{Symmetrical Loading}

When a steel beam is symmetrically loaded, the elastic stability theory can be used to predict the elastic capacity of the beam. If the steel beam is subjected to uniform bending, the critical moment governing the buckling of the beam can be expressed as [13]:

$M_{c r}=\frac{\pi^{2} E I_{y}}{l^{2}}\left[\beta_{y}+\sqrt{\beta_{y}^{2}+\frac{I_{\omega}}{I_{y}}\left(1+\frac{G I_{t} l^{2}}{\pi^{2} E I_{\omega}}\right)}\right]$

where $M_{c r}$ is the critical moment of the beam; $I_{y}$ is the cross-sectional moment of inertia of the beam about weak axis; $E$ is the elastic modulus; $\beta_{y}$ is the asymmetry coefficient of the section of the steel beam; $I_{\omega}$ is warp moment inertia; $G$ is the shear modulus; $I_{t}$ is the free torsion constant of the section; and $l$ is lateral length without supports of the beam. 
For the steel beam subjected to vertical loads, the energy method can be employed for estimating the elastic critical maximum moment in the beam. The formula for this estimation is given as [13]:

$M_{c r}=\beta_{1} \frac{\pi^{2} E I_{y}}{l^{2}}\left[\beta_{2} a+\beta_{3} \beta_{y}+\sqrt{\left(\beta_{2} a+\beta_{3} \beta_{y}\right)^{2}+\frac{I_{\omega}}{I_{y}}\left(1+\frac{G I_{t} l^{2}}{\pi^{2} E I_{\omega}}\right)}\right]$

where $M_{\mathrm{cr}}$ is the elastic critical maximum moment, $\beta_{1} \sim \beta_{3}$ are the modified coefficients of the critical moment relevant to the types of loads, which are listed in Table 2 [13]; and $a$ is the distance from the position of loading to the shear center of the cross-section of the beam.

Table 2. Values of in $\beta_{1} \sim \beta_{3}$ Eq. 2

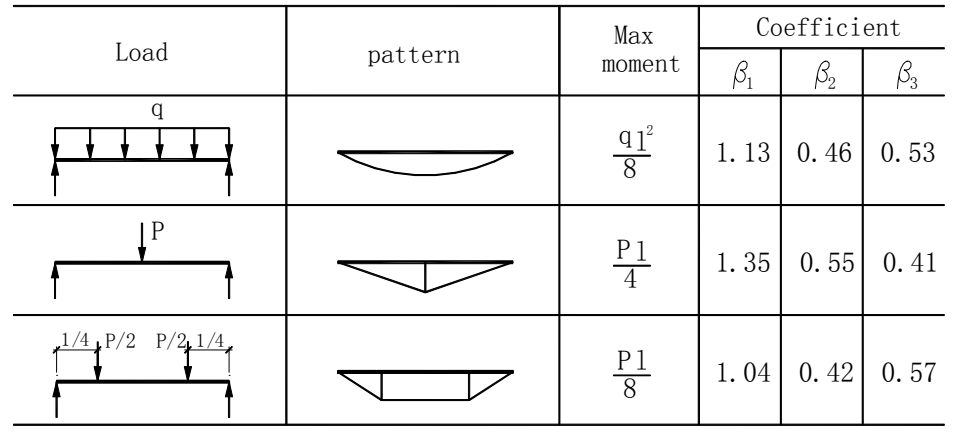

At the construction stage, the elastic critical maximum moment of the steel beam with inverted T-shaped section can be estimated with Eq. 2. Because cushion blocks are used to transmit the construction load to the bottom flange of the steel beam, the loading position is at the bottom flange, and $a$ equals 0 . Moreover the warp moment inertia of the inverted T-shaped section is nearly 0 , the elastic critical maximum moment of the steel beam with inverted T-shaped section can thus be expressed as:

$M_{c r}=\beta_{1} \frac{\pi^{2} E I_{y}}{l^{2}}\left[\beta_{3} \beta_{y}+\sqrt{\left(\beta_{3} \beta_{y}\right)^{2}+\frac{G I_{t} l^{2}}{\pi^{2} E I_{y}}}\right]$

Re-express $M_{\text {cr }}$ as:

$M_{c r}=\varphi_{b} M_{y}$

where

$\varphi_{b}=M_{c r} / M_{y}$

$M_{\mathrm{y}}$ is the initial yielding moment of the beam and $\varphi_{b}$ is the overall flexural stability coefficient. Previous studies conclude that when $\varphi_{b} \leq 0.6$, the capacity of the steel beam can be directly estimated with Eq. 4. However, when $\varphi_{b}>0.6$, plasticity may be developed in the beam, and $\varphi_{b}$ needs to be modified as $\varphi_{b}^{\prime}$ for estimating the capacity of the beam with Eq. 4.

The expression of $\varphi_{b}^{\prime}$ is given as [14]: 
$\varphi_{b}^{\prime}=1.07-0.282 / \varphi_{b} \leq 1.0$

So the moment capacity of the beam can be obtained as:

$\begin{array}{ll}M_{c r}=\varphi_{b} M_{y} & \varphi_{b}<0.6 \\ M_{c r}=\varphi_{b}^{\prime} M_{y} & \varphi_{b} \geq 0.6\end{array}$

\subsection{Un-symmetrical Loading}

When the un-symmetrical load is applied on the steel beam with inverted T-shaped section, bending and torsional deformation may be developed. Under this circumstance, the load can be decomposed into a symmetric and an asymmetric load, as shown in Figure 9.

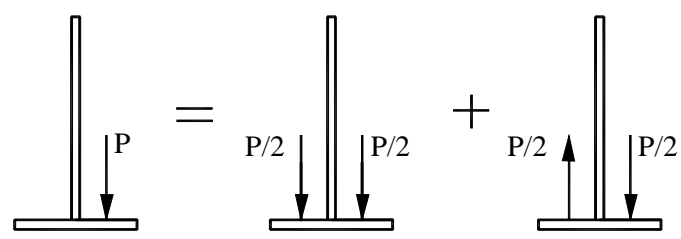

Figure 9. Decomposition of the Un-symmetrical Load

The approach proposed in 3.1 can be used for predicting the capacity of the beam under symmetric loading. When the beam is undertaken asymmetric loading, torsion is mainly developed. Because the warp moment inertia of the inverted T-shaped section is nearly 0 , the section of the beam can warp nearly freely. So there is only shear stress on the section of the beam produced by the free torsion. The shear stress can be determined with free torsion theory as:

$\tau=\frac{M_{z} t_{\max }}{I_{t}}$

where $I_{t}$ is the free torsion moment inertia; $t_{\max }$ is thickness of the thickest plate of the section; $M_{z}$ is the torque moment determined by the force and the moment arm of the force as:

$M_{z}=n c P / 4$

where $c$ is the moment arm of the force; $P$ is the concentrated load applied on one side of the bottom flange; $n$ is the number of the concentrated loads applied on the beam.

Because the bottom flange is just like a cantilever extended from the web of the steel beam, the action point of the concentrated load is close to the web provided that the cushion block has certain stiffness. So adopting $c=b_{f} / 2$ is conservative. Using the yielding criterion, the bearing capacity of the steel beam against the asymmetrical loading can be obtained be combining Eqs. 8 and 9 as:

$P_{z}=\frac{4 I_{t} f_{v}}{n b_{f} t_{\max }}$

where $f_{v}$ is the shearing strength of the steel, and $P_{z}$, is the capacity of the steel beam under the asymmetrical loads. 
The capacity of the steel beam under symmetrical loads, $P_{b}$ can be determined with the moment capacity of the beam obtained with Eq. 7. Further through using Rankine method (Y. Yao, K.H. Tan 2008), the capacity of the beam undertaken the unsymmetrical load, as shown in Figure 9 , can been estimated as

$$
\frac{1}{P_{b z}}=\frac{1}{P_{b}}+\frac{1}{P_{z}}
$$

\section{ANALYSES WITH FINITE ELEMENT METHOD}

The finite element method is employed to analyze the behavior of the steel beam with inverted T-shaped section. The FEM software package, ANSYS, is adopted for this purpose. The shell 63 element is used to simulate the web and the flange of the steel beam, and the bilinear model is adopted to simulate the elastic-plastic constitutive relation of steel. The first-order buckling mode is used to account for the shape of the initial imperfection of the steel beam, and the amplitude of the initial imperfection is determined as 1/1000 of the span of the steel beam, according to the code stipulation (GB 50017-2003).

The behavior of the test specimens of the steel beam with inverted T-shaped section are simulated with FEM, as plotted in Figure 10. The load-deflection curves of the specimens measured from tests and predicted with FEM are shown in Figure 11 and Figure 12.

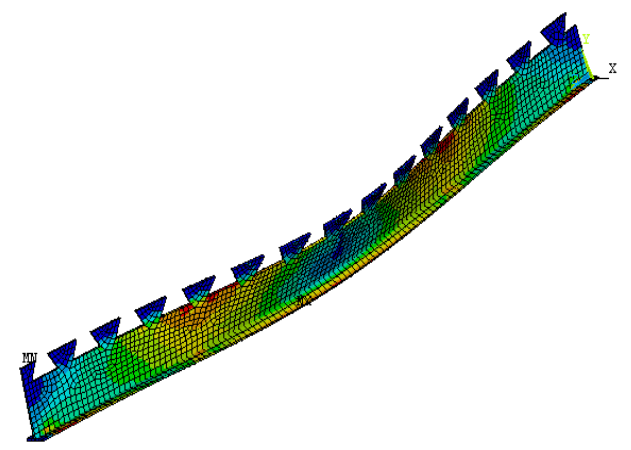

Figure 10. The FEM Model of the Test Specimens

It is demonstrated that the capacity of the specimens subjected to symmetrical loading is much higher than that of the specimens subjected to un-symmetrical loading.

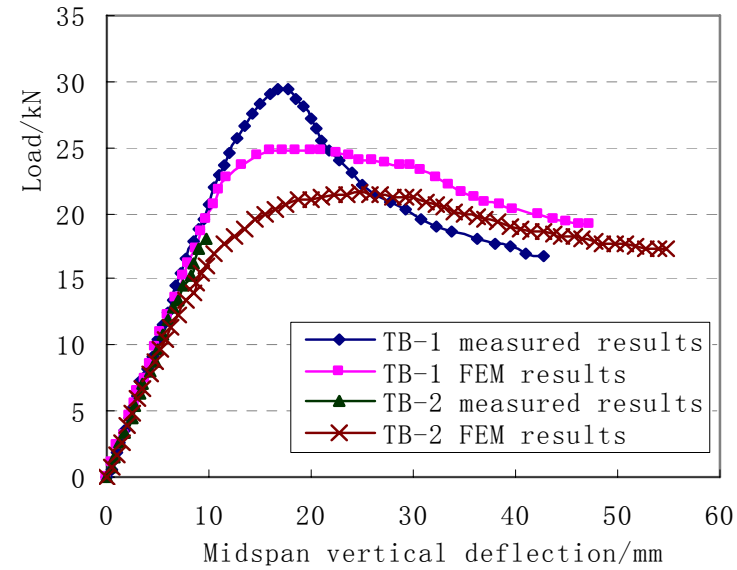

(a) Specimens TB-1 and TB-2

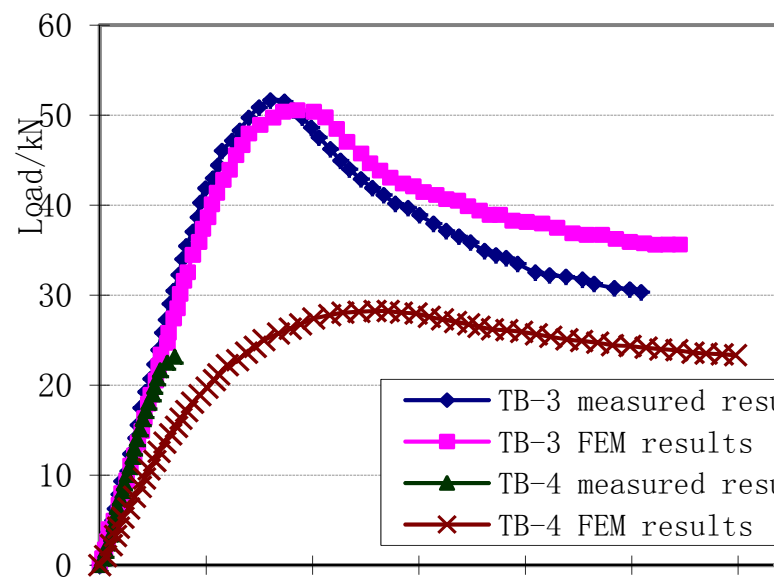

(b) Specimens TB-3 and TB-4

Figure 11. Load VS Mid-span Vertical Deflection Curves 


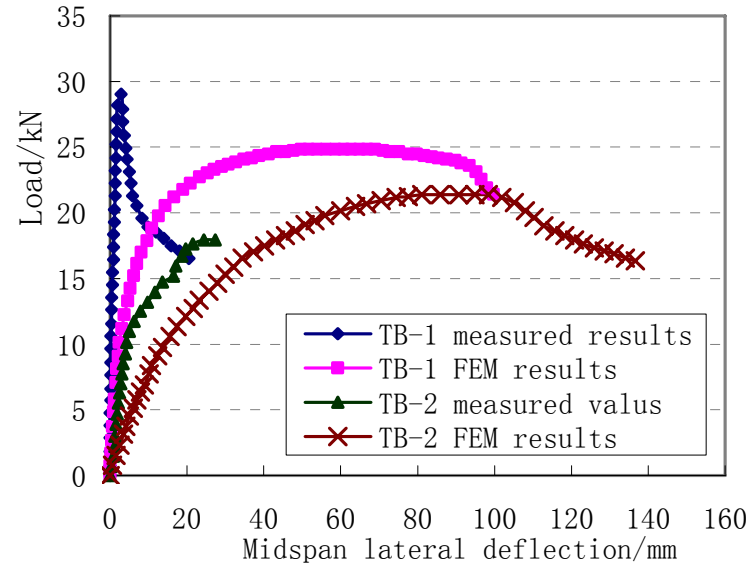

(a) Specimens TB-1 and TB-2

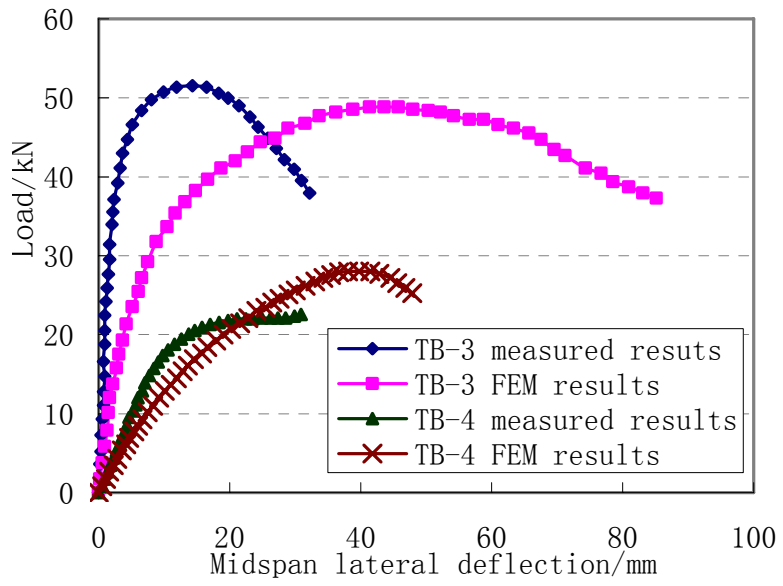

(b) Specimens TB-3 and TB-4

Figure 12. Load VS Mid-span Lateral Deflection Curves

\section{COMPARISONS}

The critical loads of all the specimens obtained from experiments, FEM simulation, and Eqs. 7 and 11 are tabulated in Table 3. It can be found that the results of the formulas proposed for predicting the critical loads of the steel beam with inverted T-shaped section agree quite well with the results of the tests and FEM analysis.

Table 3. Experimental and Analytical Results of Critical Loads of Specimens

\begin{tabular}{|c|c|c|c|c|c|c|c|}
\hline \multirow[b]{2}{*}{ NO. } & \multirow{2}{*}{$\begin{array}{l}\text { Span } \\
(\mathrm{mm})\end{array}$} & \multirow{2}{*}{$\begin{array}{l}\text { Shear } \\
\text { span } \\
(\mathrm{mm})\end{array}$} & \multicolumn{3}{|c|}{ Critical loads $(\mathrm{kN})$} & \multicolumn{2}{|c|}{ Relative difference } \\
\hline & & & measured & FEM & Eqs. & $\begin{array}{l}\text { FEM to } \\
\text { measured }\end{array}$ & $\begin{array}{c}\text { Eqs to } \\
\text { measured }\end{array}$ \\
\hline TB-1 & 3360 & 980 & 28.8 & 26.5 & 23.5 & $-6.9 \%$ & $-11.3 \%$ \\
\hline TB-2 & 3360 & 980 & 17.9 & 21.1 & 16.9 & $15.1 \%$ & $-5.6 \%$ \\
\hline TB-3 & 3640 & 1070 & 53.5 & 52.1 & 48.6 & $2.6 \%$ & $-9.1 \%$ \\
\hline TB-4 & 3640 & 1070 & 23.5 & 27.8 & 28.3 & $15.4 \%$ & $16.9 \%$ \\
\hline
\end{tabular}

Note: The results of Eqs in the table above are obtained with Eqs. 7 and 11.

\section{CONCLUSIONS}

Experimental and analytical investigation on the over stability of the steel-concrete composite beam with notched web of inverted T-shaped steel section at construction stage has been conducted in this paper. The conclusions may be drawn as follows:

(1) The cushion blocks can be used to support the construction load applied on the steel beams with inverted T-shaped section in engineering practice, which is benefit to increase the lateral stability of the steel beams consisting of the steel-concrete composite beams.

(2) The buckling failure modes of the steel beams with inverted T-shaped section are all flexural torsion type no matter the steel beams are symmetrically or un-symmetrically loaded.

(3) The formulas obtained from theoretical analysis can predict quite well the capacities of the steel beams with inverted T-shaped section under either symmetrically loading or un-symmetrically loading. 


\section{ACKNOWLEDGEMENTS}

The work reported hereinabove is financially supported by the ministry of science and technology of China through the projects SLDRCE08-A-06 and by the National Science Foundation of China through the project No. 50738005, which are gratefully acknowledged.

\section{NOMENCLATURE}

a The distance from the load position to the shear center of the steel beam section

$b_{f} \quad$ The width of the bottom flange

$f_{v} \quad$ The shearing strength of the steel

$l \quad$ Lateral length without supports of the member

$n \quad$ The number of the forces

$t_{\max } \quad$ The thickness of the thickest plate

E The elastic modulus

$G \quad$ The shear modulus

$I_{y} \quad$ The cross sectional moment of inertia to y axis

$I_{\omega} \quad$ Warp moment inertia

$I_{t} \quad$ The free torsion constant of the section

$M_{c r} \quad$ The critical moment

$M_{y} \quad$ The moment of yielded at the edge of the section

$M_{z} \quad$ The torque moment determined

$P \quad$ Force applied at one side of the bottom flange

$P_{b z} \quad$ The bearing capacity of the steel beam under bending and torsion

$P_{b} \quad$ The bearing capacity of the steel beam under bending

$P_{z} \quad$ The bearing capacity of the steel beam under torsion

$\beta_{y} \quad$ The asymmetry coefficient of the section of the steel beam

$\beta_{1} \quad$ The modified coefficient of the critical moment determined by different types of loads

$\beta_{2} \quad$ The influence coefficient determined by position of the load point at the section

$\beta_{3} \quad$ The modified coefficient to monosymmetry section at different types of loads

$\varphi_{b} \quad$ The general stability coefficient

\section{REFERENCES}

[1] Newmark, N.M., Siess, C.P. and Viest, I.M., “Test and Analysis of Composite Beams with Incomplete Interaction. Experimental Stress Analysis, 1951, Vol. 9, No. 6, pp. 896-901.

[2] Johnson, R.P., "Partial-interaction Design of Composite Beams", The Structural Engineer, 1975, Vol. 3, No. 8, pp. 1-21.

[3] Crisinel, M., "Partial-interaction Analysis of Composite Beams with Profiled Sheeting and Non-welded Shear Connectors”, Journal of Construction Steel Research, 1990, Vol. 15, pp. 65-98.

[4] Grant, J.A. and Fisher, J.W., “Composite Beams with Formed Steel Deck”, Engineering Journal, AISC, 1977, Vol. 14, No. 1, pp. 24-43.

[5] Higgins, Christopher, "Behavior of Composite Bridge Decks with Alternative Shear Connectors”, Journal of Bridge Engineer, 2001, pp. 17-22. 
[6] Galambos, T.V., "Recent Research and Design Developments in Steel and Composite Steel-concrete Structures in USA”, J. Constructional Steel Research, 2000, Vol. 55, No. 1, pp. 289-303.

[7] Roger, G. Slutter, "Flexural Strength of Steel-concrete Composite Beams", Proceedings of ASCE, Journal of the Structural Division, 1965, Vol. 91, No. 4, pp. 71-99.

[8] Uy, B., “Application Behavior and Design of Composite Steel-concrete Beams Subjected to Combined Actions", Proceedings of the $9^{\text {th }}$ International Conference on Steel Concrete Composite and Hybrid Structures (ASCCS 2009), Leeds, UK, July 2009.

[9] Eurocode 4, "Design of Composite Steel and Concrete Structures, Part 1.1: General Rules and Rules for Buildings”, 1994.

[10] Li, X.H. and Li, G.Q., "Push-out Experimental Study on Shear Connectors in Embedded Composite Beams with Notched Web”, J. Journal of Building Structures, 2009, Vol. 30, No. 4, pp. 78-84.

[11] Li, X.H. and Li, G.Q., "Pull-out Experimental Study on Shear Connector in Embedded Composite Beams with Notched Web”, J. Journal of Architecture and Civil Engineering 2009, Vol. 26, No. 1, pp. 43-48.

[12] Li, G.Q. and Li, X.H., "Study on a Novel Steel-concrete Composite Beam”, ICASS '09 / IJSSD / IStructE Asia-Pacific Forum Sixth International Conference on Advances in Steel Structures. Nov., 2009.

[13] Cheng, J., "Stability of Steel Structures Theory and Design (2 $\left.{ }^{\text {nd }}\right)$ ”, [M] Beijing: Science Press, 2003 (in Chinese).

[14] GB50017-2003, Code for Design of Steel Structures, [S] 2003 (in Chinese). 